\title{
“UTOPIAPA" E "DISTAPIOCA": UMA ANÁLISE DE A REVOLUÇÃO DOS HOMENS E ADMIRÁVEL BRASIL NOVO
}

\section{Victor de Barros Rodrigues ${ }^{1}$}

\begin{abstract}
Resumo: Neste artigo, será analisado o caráter utópico e distópico das obras Admirável Brasil Novo, de Ruy Tapioca, e A Revolução dos Homens, de Wilson Rio Apa. Percebe-se que, ao contrário de romances utópicos, os romances distópicos são conflitantes, possuem caráter crítico, denunciativo de questões sociais, como o aumento dos grandes centros, o individualismo e a ideologia.
\end{abstract}

Palavras-chave: Utopia, distopia, ficção, tecnologia.

Abstract: In this article, we will analyze the utopian and dystopian character of the works Admirável Brasil Novo, by Ruy Tapioca, and A revolução dos Homens, by Wilson Rio Apa. We can noticed that, unlike utopian novels, dystopian novels try to show conflict, criticism about social issues, such as the increase of big urban areas, individualism and ideologies.

Keywords: Utopia, dystopia, fiction, technology.

\section{Introdução}

A massificação e desvalorização do homem, a supervalorização das máquinas, a expansão dos grandes centros e o progresso tecnológico são temas constantes nas obras de Ruy Tapioca e Wilson Rio Apa. Neste artigo serão analisados os caráteres utópico e distópico dos livros A Revolução dos Homens e Admirável Brasil Novo, sob a ótica do livro A Utopia, de Thomas More.

\section{Utopia, distopia e o gênero ficção}

A profetização pessimista sobre o futuro do mundo não é novidade na literatura universal. No aclamado livro 1984, de George Orwell, publicado em 1949, veicula-se uma feroz crítica à aniquilação da identidade e do pensamento individualista e ao condicionamento dos indivíduos a determinados comportamentos massificados por um sistema opressor e totalitário da sociedade. O clássico Fahrenheit 451, de Ray Bradbury, publicado em 1953, envolve a função inversa do ofício de bombeiro, ou seja, atear fogo ao invés de apagá-lo, a fim de destruir livros que pudessem influenciar o pensamento das pessoas, diminuindo, portanto, a possibilidade de singularidade em meio ao coletivo. Por fim, com publicação anterior, surgia, em 1932, a obra Admirável Mundo Novo, de Aldous Huxley, a qual centraliza uma crítica ao

\footnotetext{
${ }^{1}$ Graduado em Letras (PUC-PR), aluno da pós-graduação em Literatura Brasileira e História Nacional (UTFPR).
} 
progresso técnico e científico da humanidade.

É comum essas três obras serem caracterizadas como romances distópicos, termo tido como antítese de utopia. O termo "utopia” (do grego 'ou' + 'tópos', o "não-lugar", ou seja, lugar que não existe, imaginário) fora criado por Thomas More em 1516, ano de publicação do célebre Utopia, para designar um local ideal para o desenvolvimento sem limites da sociedade, inatingível a qualquer outra, e propício a despertar a felicidade em todos os seres humanos, negando, dessa forma, a sociedade real.

É com o surgimento da ficção científica - fruto das revoluções industriais e científicas - e de autores como Julio Verne e H. G. Wells, em meados do século XIX, que a utopia abordada em um tempo futuro conquista um aspecto otimista em relação ao progresso tecnológico. Segundo Christiane Zschirnt, "as utopias dos séculos XVI e XVII eram ilhas distantes, alcançadas por navios. As modernas utopias dos séculos XIX e XX não se situam mais em lugares inexplorados da Terra, mas no futuro, e são alcançadas pelo caminho do progresso" (2006, p. 307).

O professor Mateus Yuri Ribeiro da Silva Passos (2004) afirma que a maior parte da literatura distópica está inserida no gênero ficção científica. Assim, autores como Huxley, Orwell e Bradbury discorrem e consolidam o termo distopia, associando-o, em seus escritos, ao questionamento a respeito do impacto do progresso tecnológico sobre o comportamento da sociedade, prevendo não só um avanço sempre crescente e desordenado, mas também que esse progresso resulte - para as estruturas sociais cientificamente moldadas - regimes totalitários e alienação coletiva.

Os romances distópicos, longe de serem harmônicos como os utópicos, fornecem críticas às condições sociais e aos sistemas políticos vigentes, alertando riscos, falhas e consequências sobre sociedades altamente planejadas, bem como seus efeitos sobre os indivíduos.

Os autores distópicos criam, por meio de suas previsões e interpretações da constante mudança da vida moderna, protagonistas que não correspondem ao padrão dos personagens secundários do mundo ficcional do autor. Os famosos "heróis" não são construídos a partir de uma representação mimética, mas sim, sem deixar de se relacionar com o que é padrão, criados como uma alternativa ao comum e massificado. $\mathrm{O}$ conflito entre o protagonista do romance distópico e a sociedade na qual ele está inserido - como ocorre nos livros 1984, Fahrenheit 451 e Admirável Mundo Novo - é essencialmente significativo, pois, ao diferenciar-se dos demais personagens quando adquire a capacidade de pensar, ele progride em direção ao sonho de 
liberdade, ao rompimento com a ideologia instaurada e à restauração da identidade individual.

\section{Utopia e distopia nos romances a Revolução dos Homens e Admirável Brasil Novo}

Sob a ótica utópica e distópica, trataremos agora de dois romances brasileiros: $A$ Revolução dos Homens, escrito em 1967, do dramaturgo, marinheiro e escritor - mais conhecido por ter sido uma espécie de tutor do escritor Cristóvão Tezza - que certa vez criou uma comunidade teatral na cidade de Antonina/PR que, segundo uma matéria escrita por Diego Ribeiro e José Marcos Lopes, "seus feitos artísticos, se comparados, fariam dos Novos Baianos um acampamento de colegiais em férias", Wilson Rio Apa, e Admirável Brasil Novo, escrito em 2001, de Ruy Tapioca, escritor agraciado com diversos prêmios literários (entre eles o Prêmio Cruz e Souza em 2008/2009 e o Prêmio Guimarães Rosa de Literatura em 1998), que iniciou sua carreira literária somente após sua aposentadoria como empresário. Sua fama ocorre, em maior número, no ambiente acadêmico e possui quatro livros publicados, além de $O$ Admirável Brasil Novo, são eles: A Revolução dos Bugres, O Proscrito, Conspiração Barroca e O Senhor da Palavra.

A Revolução dos Homens tem como protagonista o camponês Ladislau Paciorski que, após a morte dos pais, herda o Sítio da Fonte, "como costumavam denominar a atual herança de Ladislau, era, reconheciam, o mais produtivo e bonito entre todos os daqueles campos" (APA, p. 8).

No leito de morte de seu pai, Ladislau promete-lhe cuidar da "tera", não vendê-la por "dinheirro" nenhum e "aranja" uma mulher.

Ladislau planta e cuida das terras do sítio e, como de costume, colhe o que planta para vender na cidade aos sábados. No primeiro sábado, após o falecimento de seu pai, incumbido da promessa de arranjar uma esposa, parte para a cidade. Determinado e convicto, pede uma de suas clientes em casamento, noivando, no mesmo dia, com Francisca.

A união com Francisca resulta-lhe duas filhas, Mariúcha e Estefânia, e, mais tarde, um filho, Joseph. Com o passar do tempo, a ida à cidade aos sábados não deixara de ser o acontecimento da semana, porém, sem perceber as mudanças que ocorriam na paisagem urbana, Ladislau não notava o progresso vindo do norte. O camponês só ocupava a mente com mudas, podas e enxertos, tal como uma "ilha cercada de vegetais por todos os lados, vegetais que o impediam ver a tempestade iminente" (APA, p.19), deixando de lado a transformação da cidade em metrópole. 
Com o grande aumento do tráfego na cidade, Ladislau envolve-se em um acidente de trânsito pela lentidão e falta de coordenação de sua carroça e é levado pelos policiais até a delegacia, onde o agridem e prendem, o que desperta, nesse momento, a raiva do camponês contra as máquinas.

A raiva de Ladislau não ficara apenas voltada para as máquinas, mas também aos policiais e à própria cidade, que já não era mais como ele a conhecera por conta das transformações bruscas, as injustiças, o desrespeito, a expansão pelo campo, o excesso de pessoas, transformando em raiva tudo o que simbolizasse o progresso material. Seu ódio aumenta quando Mariúcha foge de casa para se aventurar com um policial, e tortura-se, como se a cidade tivesse roubado sua filha.

A expansão da cidade e das estradas afetam os vizinhos de Ladislau, que vendem suas terras e migram para a cidade. Ofertas tentadoras seduzem Francisca e Estefânia, levando-as a tentar convencer Ladislau a vender o sítio e mudar-se para a cidade, o que, segundo o comprador interessado nas terras, lhes concederia melhores condições de vida, um trabalho mais leve do que o de agricultores e, ainda, melhor futuro para os filhos. Contudo, o camponês mantém-se firme perante a promessa feita a seu pai e a sua vontade de não abandonar a terra, causando grandes intrigas com a esposa e com a filha por conta de suas visões utópicas sobre o meio urbano.

Com o passar do tempo e o avanço gradativo da cidade, Ladislau é obrigado a deixar as terras, sem receber dinheiro algum por elas, por não possuir escritura ou documento algum que lhe assegurasse a posse. Muda-se com a família para a cidade e entra em profunda depressão.

Na cidade, habitando um galpão de famílias sem terras, Joseph, seu filho mais novo, desaparece. Ladislau retoma as energias e parte, sozinho, enfrentando a tão destemida cidade para encontrar o filho recém-perdido e a filha que há anos o abandonara.

O camponês cria uma estreita relação de amizade com Armindo, Xixo, Jeremias e Osvaldo, que o ajudam a procurar os filhos e a sobreviver na cidade. Juntos, procuram por espaços inutilizados nos prédios e na cidade e passam a plantar flores, verduras, legumes e, após encontrarem Mariúcha, plantam árvores na cobertura de seu prédio, fazendo, assim, o que eles denominam de "a revolução dos homens".

Sonhando em voltar ao campo, Ladislau propõe-se a arranjar um emprego na cidade para, junto a Mariúcha e Armindo, que se casariam em breve, juntar dinheiro. Começa a trabalhar - contra sua vontade - como ascensorista, com receio de que a máquina um dia lhe 
trouxesse transtornos. Após algum tempo de trabalho, Ladislau sofre uma crise nervosa por causa do estresse que o emprego lhe causava.

Um dia, sem ainda ter reencontrado Joseph, Estefânia e Francisca, o elevador que Ladislau coordenava se interrompe no meio da atividade pela alta carga de passageiros, que, transtornados pela claustrofobia, se agitam e, descontroladamente, agridem Ladislau quando este tentava acalmá-los. O camponês é morto dentro do elevador, colocando fim ao desejo de reencontrar os familiares e a voltar a morar no campo. É perceptível, na trágica morte de Ladislau, a vitória do coletivo sobre o singular, do urbano sobre o rural.

O romance distópico de Ruy Tapioca, Admirável Brasil Novo, escrito em 2001, sob o mandato do então presidente da República Fernando Henrique Cardoso, é protagonizado pelo jornalista Lázaro das Dores, de 45 anos, e tenta investigar a sociedade brasileira em 2045. A visão decadente de Tapioca com o Brasil do futuro é refletida na ideologia do protagonista Lázaro, o qual, diferente de sua esposa e do resto do País, fica inconformado com o sonho da filha mais nova de ser a estrela do "bundaxé".

A distopia de Tapioca refletida em Lázaro dispõe de uma sociedade brasileira que alcança o grau máximo de "idiocracia" com uma televisão sensacionalista e vulgar, com o bundaxé como a dança do futuro, a música "sertanoforrogode" fazendo enorme sucesso e, além da publicação massiva de livros esotéricos e de autoajuda, com a literatura do "romance compacto minimalista", cujo principal nome é o de Astrid Junqueira (amante de Lázaro), que publicara livros com títulos referentes a nomes de preposições e conjunções e não mais do que um parágrafo, tais como: contudo, todavia, em, mas, e, por último, “!”, com o qual ganhou diversos prêmios literários e propostas de traduções para diversos países (mesmo o livro contendo 100 páginas em branco, as quais, segundo a autora, são para que o leitor tenha liberdade de criar a história e se sentir autor de uma obra literária), sendo, posteriormente, eleita para Academia Brasileira de Letras. Lázaro não entende como livros desse gênero, dessa qualidade possam ser sucesso de vendas, haja vista que ele é um leitor de clássicos do século XX, como Graciliano Ramos.

O presidente da República é um bispo evangélico “com nome de dupla caipira”, Miron Marian, filiado ao Partido da Purificação da Nova Vida, com o nepotismo institucionalizado e os partidos políticos divididos entre "conformistas" e "inconformistas", termos sucessores, respectivamente, a "direita” e "esquerda”. Além disso, em 2045, o acesso às praias da baía só é permitido por meio do uso dos tíquetes-praia para a prática de cultos religiosos, futebol de areia, vôlei e assistência a shows de música sertaneja e pagodes. 
Importante notar também a extinção de quase cinco centenas de profissões por conta da globalização e do desenvolvimento tecnológico desenfreado, a instalação de sinais reguladores de controle de tráfego humano, de funcionamento articulado com os de trânsito de veículos, a necessidade de aterramento e asfaltamento da Lagoa Rodrigo de Freitas, no Rio de Janeiro, por conta do déficit de garagens residenciais e de estacionamentos e a existência de CDs que reproduzem sons e gritarias característicos de shopping center que são prescritos por médicos para terapia de sono.

Nas eleições de 2045, o partido conformista do atual presidente e candidato a reeleição Miron Marian só poderá receber o empréstimo bilionário da Eurobank que pode tirar o Brasil da falência se o vice-presidente pertencer ao Partido Ecolaboral, inconformista, pois o vice é o único que tem controle de um Banco Central independente. O político escolhido para integrar a comissão junto ao Partido da Purificação da Nova Vida é Antônio Péricles, cidadão íntegro, negro (o racismo ainda é vigente naquele futuro) e deficiente físico (alcunhado de forma satírica por alguns como Malfeito). Antônio Péricles elabora o Plano dos Dez Pontos, capaz de tirar o País da falência e restituir a dignidade do povo.

Miron e Antônio Péricles vencem as eleições, mas, pouco tempo depois, o presidente Miron Marian sofre um ataque cardíaco e morre, deixando o cargo de presidente para Antônio Péricles e gerando a revolta dos ministros conformistas aos quais o presidente falecido havia prometido generosas e impossíveis recompensas financeiras. Com a posse de Antônio Péricles, o cargo de porta-voz da presidência da República é encubido a Lázaro das Dores.

Os ministros revoltados planejam uma enrascada para Antônio Péricles na ponte RioNiterói. Dirigirem o carro presidencial até o local marcado e lá, dentro do carro, o ministro Krammer retira uma pistola de um compartimento ao lado do seu assento e com ela dispara quatro tiros certeiros: os dois primeiros atingem a cabeça do presidente Antônio Péricles e os outros dois, a cabeça do prefeito do Rio de Janeiro, Stalin Guevara. Grande quantidade de sangue e pedaços das massas encefálicas das vítimas espirraram no teto do veículo. Lázaro é retirado à força de dentro do carro e jogado na baía. Após cruzar a crosta pastosa do mar escuro, sentiu o corpo mergulhar. Submerso, notou que ainda estava vivo. Enquanto esboçava o retorno à superfície, ouviu um grito de dor. O grito veio de uma mulher grávida chamada das Dores que é prontamente atendida pelo marido, chamado Lázaro.

Esses dois são os pais de Lázaro das Dores, no ano 2000, poucos dias antes de Lázaro nascer, levando a crer que o futuro distante previsto não passou de um sonho de quem ainda estava por vir ao mundo. Longe dali, na Paraíba, um agricultor sem-terra, negro e miserável, ao 
lado da mulher grávida pensavam a respeito do nome do futuro filho: caso seja mulher, se chamará Esperança, caso seja homem, Antônio Péricles.

\section{Considerações finais}

Percebe-se, a partir do estudo dos livros Admirável Brasil Novo e A revolução dos Homens, que romances distópicos possuem forte crítica à idiocracia, ao progresso tecnológico e científico da humanidade, à corrupção, massificação e desvalorização do homem e ao aumento gradativo das cidades.

Os protagonistas de livros distópicos fogem do padrão do mundo ficcional de livros utópicos, de heróis, com finais felizes, para possuir uma visão realista sobre o futuro, uma visão próxima da decadência de estilos, gostos, opiniões, etc. e com desfechos nem sempre felizes, que acompanham esse caráter crítico.

\section{Referências}

APA, Wilson Rio. A Revolução dos Homens. Rio de Janeiro: José Olympio, 1967.

MORUS, Tomás. A Utopia. Porto Alegre: L\&Pm, 1997.

PASSOS, M. Y. R. S. Distopias: Presságios de Um Futuro Nefasto. Estudos do Futuro, São Paulo v. 1, n. 1, fev. 2007. Disponível em: <http://www.nef.org.br/revista.1/11>. Acesso em: 05 jun. 2013.

RIBEIRO, Diego; Lopes, Jose Marcos. Perguntem ao Rio. Disponível em: <http://www.gazetadopovo.com.br/entrevistas/conteudo.phtml?id=1180956\&tit=Perguntem-ao-Rio>. Acesso em: 20 jun. 2013.

TAPIOCA, Ruy. Admirável Brasil Novo. Rio de Janeiro: Rocco, 2001.

ZSCHIRNT, Christiane. Livros. São Paulo: Globo, 2006. 